\title{
Investigation on standoff distance influence on kerf characteristics in abrasive water jet cutting of composite materials
}

\author{
Ioan Alexandru POPAN ${ }^{1, *}$, Glad CONTIU ${ }^{1}$, and Ian CAMPBELL ${ }^{2}$ \\ ${ }^{1}$ Technical University of Cluj-Napoca, B-dul. Muncii, 400641, No. 103-105, Cluj-Napoca, Romania \\ ${ }^{2}$ Loughborough University, Leicestershire, LE11 3TU, Loughborough, UK
}

\begin{abstract}
The paper presents an experimental study on processing composite materials using abrasive water jet cutting (AWJC) process, analysing one of the main process parameter, standoff distance (SOD). Carbon Fibre Reinforced Plastics (CFRP) are used in a wide range of industrial applications, like aerospace and automotive. Cutting CFRP using AWJC involves several challenges like high dimensional accuracy and good surface quality. To produce precise parts by using this process must be understand the influence of the process parameters on quality characteristics. On this study was investigated the standoff distance influence on kerf characteristics. The characteristics of the cut surface (kerf geometry, surface roughness and topography) were analyzed.
\end{abstract}

\section{Introduction}

Composite materials like Carbon Fibre Reinforced Plastics (CFRP) have wide applications in aerospace, automotive, marine goods, medical fields etc $[1,2]$. The main characteristics of CFRPs are: high strength to weight ratio, high modulus, high fracture toughness, corrosion and thermal resistance [3, 4].

Water jet processing uses pressurized water, which acts either by itself at a very high pressure, or in connection with the erosion of the abrasive particles, added into the water jet [5]. Abrasive water jet is used in various machining operations, like cutting [6], milling [7], drilling [8] and turning [9]. This innovative processing solution can be applied in processing for a wide range of materials like aluminium [10], steel [11], stainless-steel [12], composites [13], titanium alloy or even ceramics and diamond [14].

Abrasive water jet cutting (AWJC) process is a proper solution for cutting CFRP because of reduced interface temperature, low mechanical loading, better surface integrity, low tool wear, and small cutting forces $[15,16]$. AWJC is a complex process with a large number of parameters, like water pressure, feed rate, abrasive mass flow, standoff distance, etc. [17-20]. The main quality characteristics of the cut parts are: kerf geometry [21], surface roughness [22] and topography [23]. S. Vasanth noticed in his research on titanium alloy processing using AWJC, that abrasive flow rate and standoff distance have a

\footnotetext{
*Corresponding author: ioan.popan@tcm.utcluj.ro
} 
significant role on determining surface quality. A higher standoff distance (SOD) produces higher surface roughness due to larger and random energy distribution.

Higher SOD allows the waterjet to expand before impingement on the workpiece which may increase the exposure to external drag from the surrounding environment. Thus with the increase in SOD, the jet diverges which results in decreasing the kinetic energy of the jet and thus producing a rough surface $[5,14,24]$. The SOD has effect on kerf geometry, manly on the kerf taper angle and on the top edge radius [25].

The surface cut by AWJC is divided in three zones: initial damage zone, smooth cutting zone and rough cutting zone (figure 1) [26-27]. To understand the influence of the standoff distance on surface quality, each zone must be analysed.

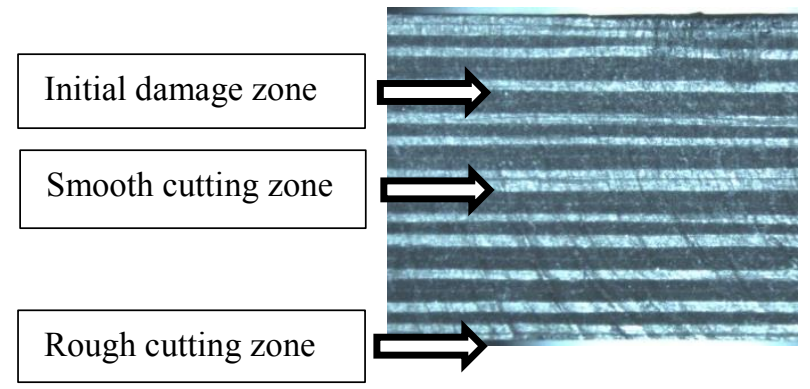

Fig. 1. The main zones of a surface cut by AWJC.

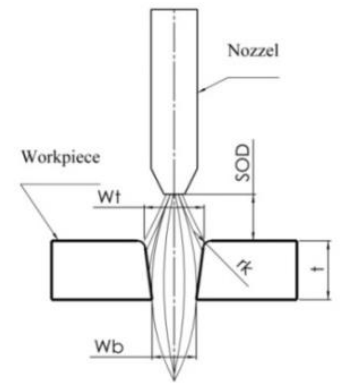

Fig. 2. The kerf geometry.

In this paper the influence of standoff distance (the distance between cutting head and work-piece) on the characteristics of the cut surface is studied.

\section{Experimental procedure}

In this experimental study, the standoff distance SOD is the variable process parameter. The main characteristics of the cut surface (kerf geometry, surface roughness and topography) were analyzed. Ra / Sa average roughness, Rz / Sz average maximum height of the profile, were the surface roughness parameters studied. The analysed kerf geometry dimensions were: $\mathrm{W}_{\mathrm{t}}$ - the top kerf width, $\mathrm{W}_{\mathrm{b}}$ - the bottom kerf width and $\mathrm{r}_{\mathrm{k}}$ - the top edge radius, presented in figure 2. The constant parameters and the values for SOD used on this study are presented in table 1.

Table 1. Process parameters used in the experiments.

\begin{tabular}{|l|l|}
\hline Technological parameter & Value \\
\hline Sample thickness & $6 \mathrm{~mm}$ \\
Pressure & $355 \mathrm{MPa}$ \\
Feed rate & $100 \mathrm{~mm} / \mathrm{min}$ \\
Abrasive type / size & Australian Garnet / 80 mesh \\
Abrasive mass flow & $0.440 \mathrm{~kg} / \mathrm{min}$ \\
Nozzle diameter & $0.76 \mathrm{~mm}$ \\
Orifice diameter (diamond) & $0.35 \mathrm{~mm}$ \\
Standoff distance & $\mathbf{0 . 5} \mathbf{1 ; 2} \mathbf{2} ; \mathbf{4 ;} \mathbf{5} \mathbf{~ m m}$ \\
\hline
\end{tabular}

The experimental trials were conducted using an Omax 2626, 3-axis abrasive waterjet system (figure 3). It has an OMAX high pressure pump with an output pressure of maximum $400 \mathrm{MPa}$ and the maximum feed rate is $4500 \mathrm{~mm} / \mathrm{min}$.

The material used in this study is a multi-layer composite material consisting of carbon fibre reinforced plastics (CFRP): ECOTECH ${ }^{\mathrm{TM}}$, made out of HT carbon fiber pre-pregs with a transparent epoxy resin matrix in press molding. One surface layer consists of $3 \mathrm{k}-$ 
fabric style 452 in twill weave $2 / 2$ (fabric pre-preg CE 8201-200-45). The core layer consists of $3 \mathrm{k}$ UD-non-crimp fabric $0^{\circ} / 90^{\circ}$ (bidirectional) [28].

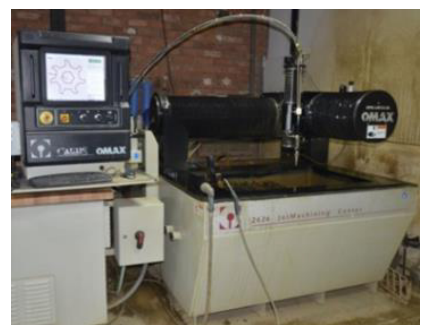

Fig. 3. The water jet machine Omax 2626.

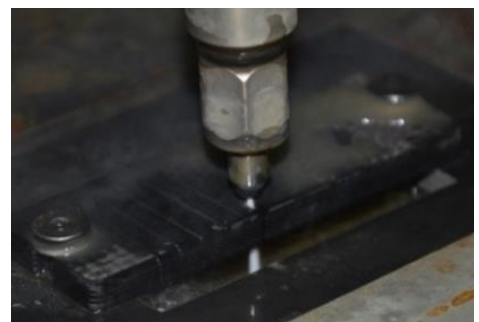

Fig. 4. The clamping system.

The specimens had the dimensions: $100 \times 35 \times 6 \mathrm{~mm}$ and they were fixed in the clamping system presented in figure 4 .

\section{Results and discussions}

In this section, the influence of standoff distance SOD on kerf geometry, surface roughness and surface topography has been analyzed.

\subsection{Influence of the standoff distance on kerf geometry}

To measure the dimensions of kerf geometry the PG 2000 microscope was used with $9.5 \mathrm{x}$ zoom. In figure 5 the obtained kerf geometry with different values of SOD $(0.5 ; 1 ; 2 ; 3 ; 4 ; 5$ $\mathrm{mm})$ is presented.

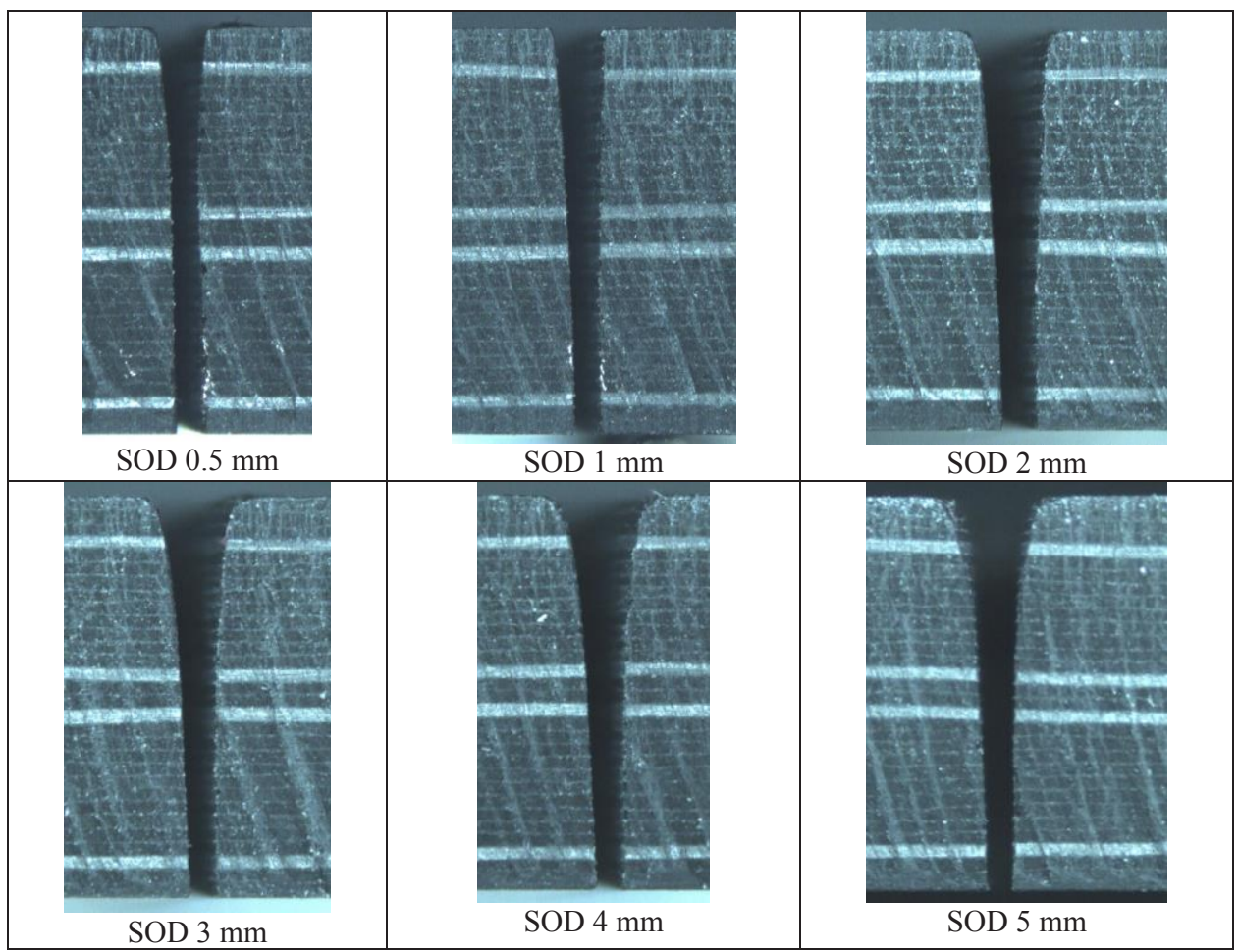

Fig. 5. The kerf geometry obtained with different values of SOD. 
The kerf geometry dimensions: $\mathrm{W}_{\mathrm{t}}$ - the top kerf width, $\mathrm{W}_{\mathrm{b}}$ - the bottom kerf width, $\mathrm{r}_{\mathrm{k}}$ the top edge radius are presented in table 2.

Table 2. The kerf geometry dimensions.

\begin{tabular}{|c|c|c|c|c|c|c|}
\hline SOD mm & $\mathbf{0 . 5}$ & $\mathbf{1}$ & $\mathbf{2}$ & $\mathbf{3}$ & $\mathbf{4}$ & $\mathbf{5}$ \\
\hline $\mathbf{W}_{\mathbf{t}} \mathbf{~ m m}$ & 0.828 & 0.963 & 1.352 & 1.818 & 2.016 & 2.264 \\
\hline $\mathbf{W}_{\mathbf{b}} \mathbf{~ m m}$ & 0.442 & 0.457 & 0.576 & 0.497 & 0.546 & 0.526 \\
\hline $\mathbf{r}_{\mathbf{k}} \mathbf{m m}$ & 0.12 & 0.18 & 0.21 & 0.24 & 0.32 & 0.35 \\
\hline
\end{tabular}

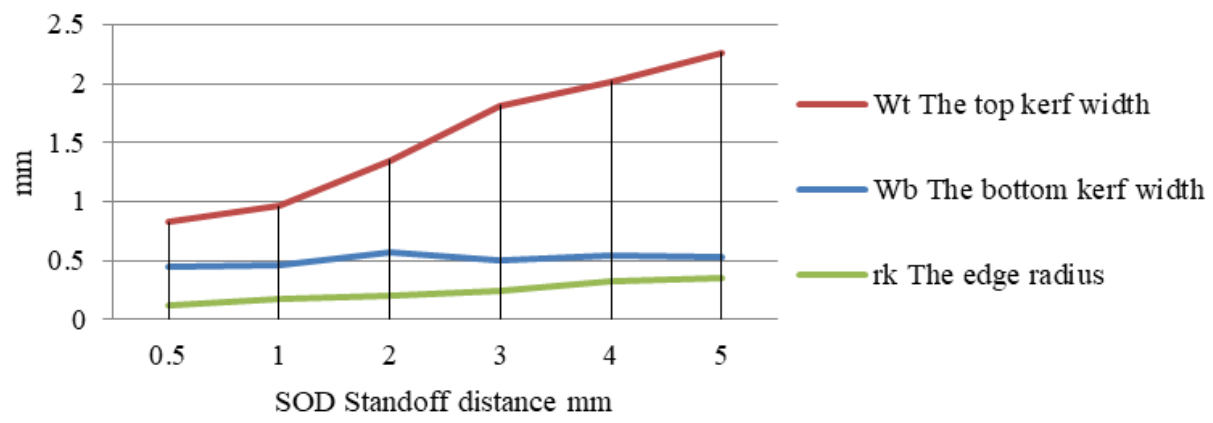

Fig. 6. The influence of the SOD on the kerf geometry dimensions.

Analysing the kerf width variation, figure 6 , can be observed that by increasing the SOD form 0.5 up to $5 \mathrm{~mm}$ the top kerf width $\mathrm{W}_{\mathrm{t}}$ increases from 0.828 up to $2.264 \mathrm{~mm}$ (red line) and the bottom kerf width $\mathrm{W}_{\mathrm{b}}$ increases from 0.442 up to $0.526 \mathrm{~mm}$ (blue line).

In case of the top edge radius $r_{k}$ represented with green line, by increasing the SOD the edge radius increases form 0.12 up to $0.35 \mathrm{~mm}$.

It can be concluded that, the SOD has a strong influence on the upper zone of the kerf, on the top kerf width and the top edge radius. It doesn't have a notable effect on the bottom kerf width. Similar aspects were observed by D.K. Shanmugam in case of abrasive waterjet machining of alumina ceramics [25].

\subsection{Influence of the standoff distance on surface roughness}

The NanoFocus 3D microscope $\mu$ surf expert was used to measure surface roughness. The surface roughness parameters: $\mathrm{R}_{\mathrm{a}} ; \mathrm{R}_{\mathrm{z}} ; \mathrm{S}_{\mathrm{a}} ; \mathrm{S}_{\mathrm{z}}$ are presented in table 3. For this measurement a Gaussian filter 0.8 was used.

Table 3. Surface roughness.

\begin{tabular}{|c|c|c|c|c|c|c|c|c|c|c|c|c|}
\hline \multirow{2}{*}{$\begin{array}{c}\text { SOD } \\
\mathrm{mm}\end{array}$} & \multicolumn{9}{|c|}{ Initial damage zone } & \multicolumn{8}{|c|}{ Smooth cutting zone } & \multicolumn{3}{|c|}{ Rough cutting zone } \\
\cline { 2 - 15 } & \multicolumn{9}{|c|}{ Surface roughness $\boldsymbol{\mu m}$ Gaussian filter $\mathbf{0 . 8}$} \\
\hline & $\mathbf{R}_{\mathbf{a}}$ & $\mathbf{R}_{\mathbf{z}}$ & $\mathbf{S}_{\mathbf{a}}$ & $\mathbf{S}_{\mathbf{z}}$ & $\mathbf{R}_{\mathbf{a}}$ & $\mathbf{R}_{\mathbf{z}}$ & $\mathbf{S}_{\mathbf{a}}$ & $\mathbf{S}_{\mathbf{z}}$ & $\mathbf{R}_{\mathbf{a}}$ & $\mathbf{R}_{\mathbf{z}}$ & $\mathbf{S}_{\mathbf{a}}$ & $\mathbf{S}_{\mathbf{z}}$ \\
\hline $\mathbf{0 . 5}$ & 1.87 & 9.82 & 2.57 & 28.9 & 2.80 & 14.1 & 4.31 & 40.6 & 2.47 & 11.9 & 4.09 & 38.4 \\
\hline $\mathbf{1}$ & 1.98 & 10.0 & 2.84 & 30.9 & 2.85 & 14.5 & 4.41 & 42.6 & 2.52 & 12.8 & 4.08 & 38.3 \\
\hline $\mathbf{2}$ & 2.21 & 11.5 & 3.60 & 36.1 & 2.90 & 14.6 & 4.54 & 44.5 & 2.50 & 12.1 & 4.10 & 40.9 \\
\hline $\mathbf{3}$ & 2.26 & 11.5 & 3.63 & 36.8 & 3.05 & 15.0 & 4.66 & 44.7 & 2.56 & 13.0 & 4.09 & 40.6 \\
\hline $\mathbf{4}$ & 2.71 & 12.8 & 3.80 & 38.5 & 3.10 & 15.6 & 4.77 & 48.7 & 2.55 & 12.8 & 4.12 & 40.9 \\
\hline $\mathbf{5}$ & 2.74 & 13.5 & 4.05 & 40.1 & 2.80 & 13.9 & 4.30 & 10.1 & 2.62 & 13.3 & 4.29 & 41.1 \\
\hline
\end{tabular}


Figure 7 represents the correlation between the standoff distance SOD and the surface roughness for each three main zones of cut surface. The SOD varied between 0.5 and 5 $\mathrm{mm}$, using an abrasive mass flow of $0.45 \mathrm{~kg} / \mathrm{min}$ and a pressure of $350 \mathrm{MPa}$.

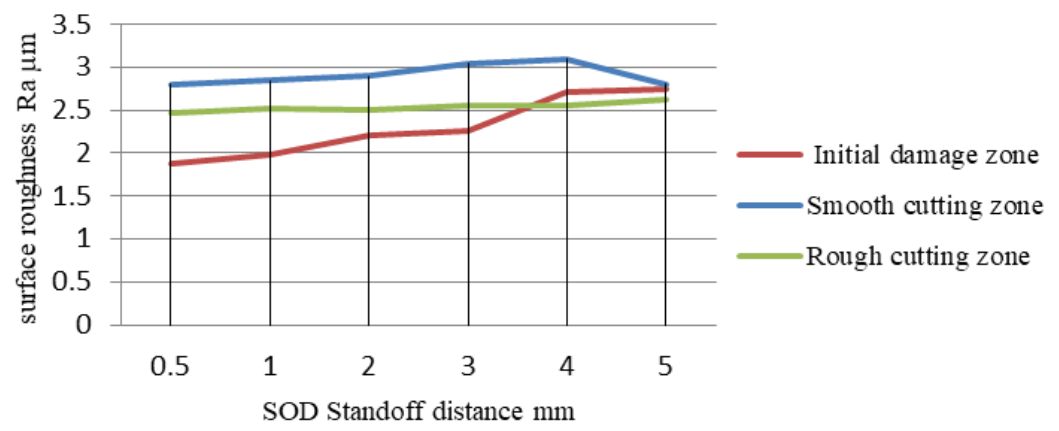

Fig. 7. The influence of the standoff distance on the surface roughness.

By variating the SOD between 0.5 and $5 \mathrm{~mm}$ the surface roughness variated between: $\mathrm{R}_{\mathrm{a}} 1.87-3.1 \mu \mathrm{m}, \mathrm{R}_{\mathrm{z}} 9.2$ - $15.6 \mu \mathrm{m}, \mathrm{S}_{\mathrm{a}} 2.57-4.77 \mu \mathrm{m}$, and $\mathrm{S}_{\mathrm{z}} 28.9-48.7 \mu \mathrm{m}$.

Analysing the surface roughness variation on the initial damage zone (represented by the red line) it can be observed that by increasing the SOD form 0.5 up to $5 \mathrm{~mm}$ the surface roughness increases $R_{a}$ from 1.87 to $2.74 \mu \mathrm{m}$ and $R_{z} 9.82$ to $13.5 \mu \mathrm{m}$.

In case of surfaces from smooth cutting zone (blue line) and rough cutting zone (green line) the surface roughness variated between $R_{a} 2.8-3.1 \mu \mathrm{m}, R_{z} 9.82-13.5 \mu \mathrm{m}$ and $R_{a}$ $2.47-2.6 \mu \mathrm{m}, \mathrm{R}_{\mathrm{z}} 14.1-15.6 \mu \mathrm{m}$ in last zone. On these zones was not observed a influence of SOD on surface quality.

However the standoff distance flow did not have a strong influence on surface quality like other main cutting parameters of the abrasive water jet process, like, pressure, feed rate and abrasive mass flow. It has a low influence on the surface roughness from the initial damage zone. The best surface quality could be obtained by minimizing this parameter, up to $0.5 \mathrm{~mm}$. This value must be correlated with the work-piece surface flatness accuracy so the focusing tube does not break.

\subsection{Influence of the standoff distance on surface topography}

The same 3D microscope was used for analysing the cut surfaces. In each main zone (initial damage zone, smooth cutting zone and rough cutting zone) a surface was scanned $1.6 \times 1.6 \mathrm{~mm}$ to obtain the 3D surfaces topography. For surface analysis was used $\mu$ soft analysis premium 7.1. The 3D surfaces topography of the cut surfaces are presented in figure 8 .

An analysis of the topography showed a smooth surface in case of CFRP processed by AWJC. By variating the SOD from 1 to $5 \mathrm{~mm}$ the $3 \mathrm{D}$ average roughness $\mathrm{S}_{\mathrm{a}}$ between 2.84 and $4.66 \mu \mathrm{m}$ (figure 8 ).

The topography of the cut surface presents a random distribution of the valleys, craters and peaks. It is dominated by deep valleys, generated by the curved trajectories of abrasive particles. These valleys have the same direction with the jet travel direction.

On the initial damage zone it can be observed a mixture of valleys and craters. Those craters are generated by abrasive grains from the outlet of the jet. Because the abrasive grains do not have enough kinetic energy to penetrate the entire thickness of material, they remove a small quantity of material from the work-piece, generating valleys and craters. 
The surface from the smooth cutting zone exhibits a random distribution of the valleys, craters and peaks. The valleys and craters depth is the smallest from the entire cut surface.

On the rough cutting zone it can be clearly observed that there are deep valleys in the same direction with the jet travel direction.

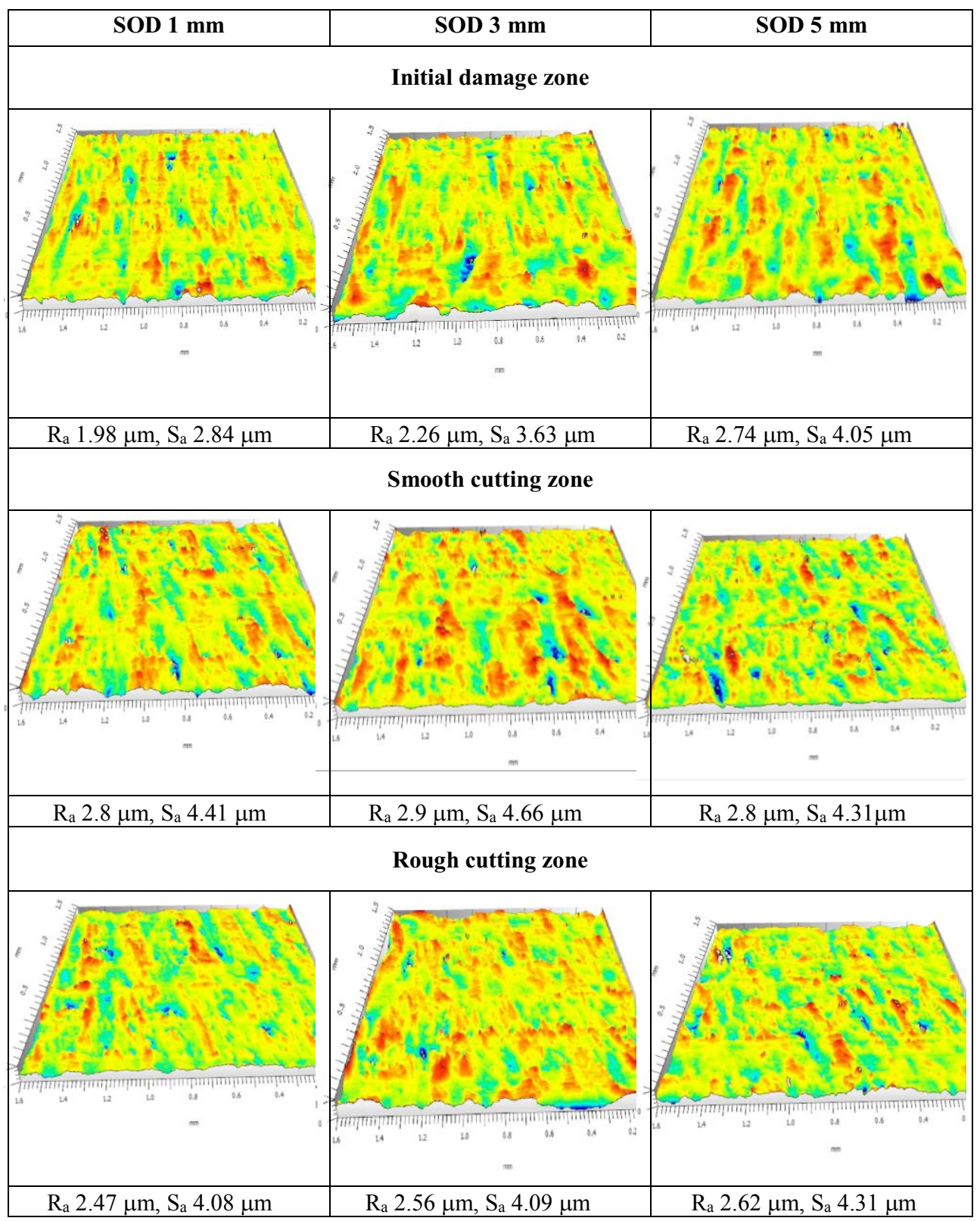

Fig. 8. The 3D surface topography of the cut surfaces.

The 2D surface roughness profiles of the cut surfaces are presented in figure 9 (a-e).

First observation after analysing the $2 \mathrm{D}$ roughness profiles is that the peaks and valleys of the profile are not symmetrical and the profile variation is not constant. 


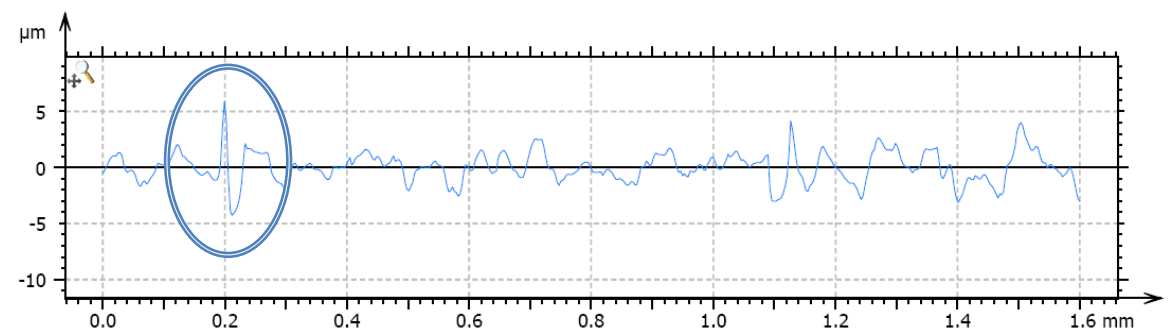

a. Initial damage zone SOD $1 \mathrm{~mm}$.

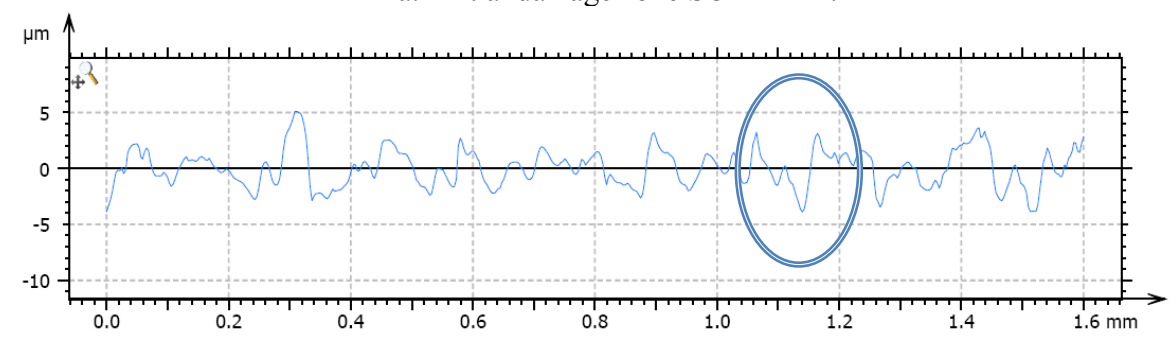

b. Initial damage zone SOD $3 \mathrm{~mm}$.

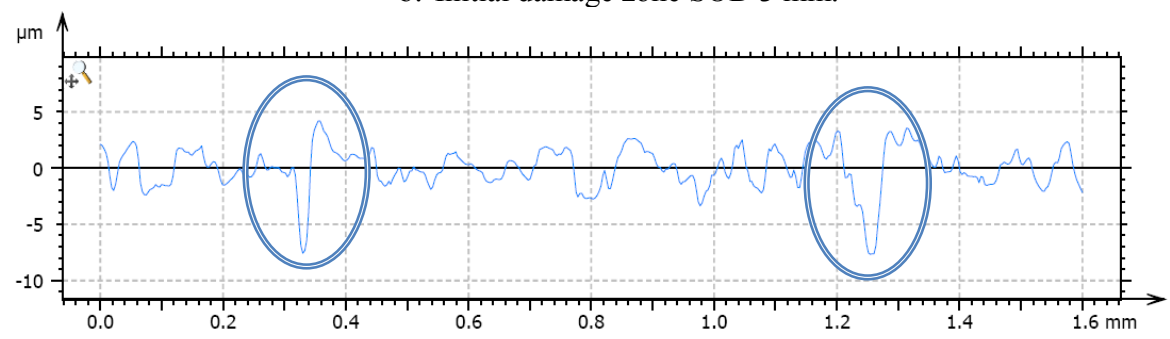

c. Initial damage zone SOD $5 \mathrm{~mm}$.

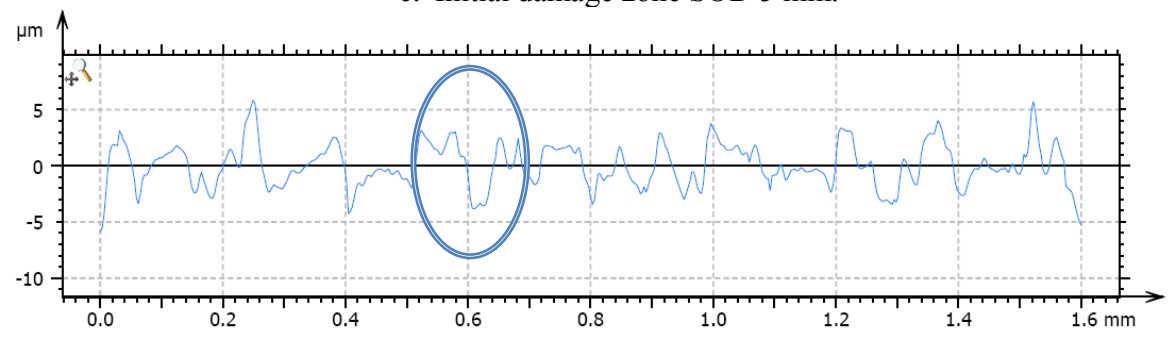

d. Smooth cutting zone SOD $1 \mathrm{~mm}$.

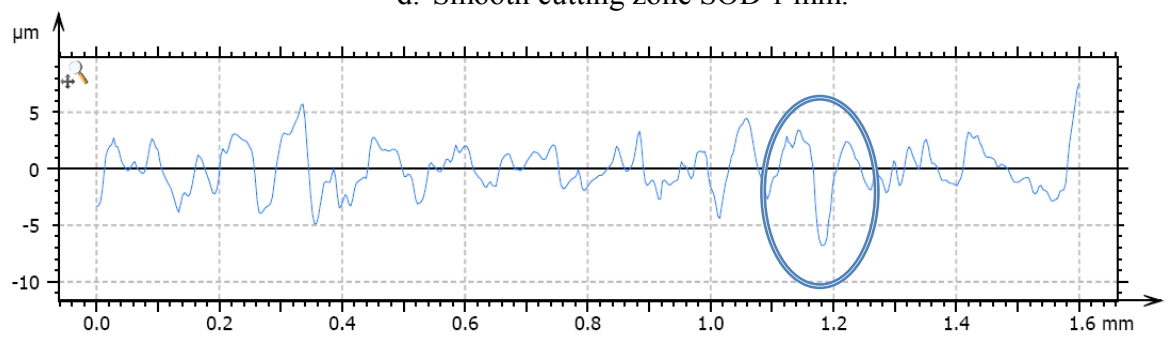

e. Rough cutting zone SOD $1 \mathrm{~mm}$.

Fig. 9. The 2D roughness profiles of the cut surfaces: a. Initial damage zone SOD $1 \mathrm{~mm}$; b. Initial damage zone SOD $3 \mathrm{~mm}$; c. Initial damage zone SOD $5 \mathrm{~mm}$; d. Smooth cutting zone SOD $1 \mathrm{~mm}$; e. Rough cutting zone SOD $1 \mathrm{~mm}$.

On the initial damage zone it can be observed that, by increasing the SOD from 1 to 5 $\mathrm{mm}$, the average maximum height of the profile $\mathrm{R}_{\mathrm{z}}$ increases from 10 up to $13.5 \mu \mathrm{m}$. For a 
value of SOD $1 \mathrm{~mm}$ a maximum valley depths of $-4 \mu \mathrm{m}$ was obtained and the valley depths is increasing up to $-8 \mu \mathrm{m}$ in case of SOD $5 \mathrm{~mm}$ (figure $9 \mathrm{a}, \mathrm{b}$ and c). The peaks height had a small variation and it is approximately $+5 \mu \mathrm{m}$.

The SOD has a low influence on surface roughness in the smooth cutting zone and rough cutting zone. A correlation between the SOD variation and the $2 \mathrm{D}$ profiles cannot be made.

In the case of the smooth cutting zone, by varying the SOD from 1-5 $\mathrm{mm}$, the average maximum height of the profile $R_{z}$ varied from 13.9 up to $15.6 \mu \mathrm{m}$. The valleys have a maximum depth of approximately $-5 \mu \mathrm{m}$ and approximately $+8 \mu \mathrm{m}$ for the peaks height (figure $9 \mathrm{~d}$ ).

In the case of the rough cutting zone the average maximum height of the profile $R_{z}$ is between 11.9 and $13.3 \mu \mathrm{m}$. In this zone the maximum valleys depth is approximately $-7 \mu \mathrm{m}$ and approximately $+7 \mu \mathrm{m}$ for the peaks height (figure $9 \mathrm{~d}$ ).

\section{Conclusions}

The standoff distance is an important parameter in machining of CFRP materials using the abrasive waterjet cutting process.

The specific conclusions from this experimental study are:

- SOD has a strong influence on the kerf geometry, mainly on the upper zone of the kerf. Decreasing the SOD up to $0.5 \mathrm{~mm}$ it was noticed that: the top kerf width $\mathrm{W}_{\mathrm{t}}$ decreases (up to $0.82 \mathrm{~mm}$ ), the bottom kerf width $\mathrm{W}_{\mathrm{b}}$ decreases (up to $0.442 \mathrm{~mm}$ ) and the top edge radius $\mathrm{r}_{\mathrm{k}}$ decreases also (up to $0.12 \mathrm{~mm}$ );

- SOD does not have a strong influence on the surface quality like other main cutting parameters of the AWJC, pressure, feed rate and abrasive mass flow. The main affected zone by the SOD variation is the initial damage zone. On this zone it was observed that by increasing the SOD from 0.5 up to $5 \mathrm{~mm}$ the surface roughness increases $\mathrm{R}_{\mathrm{a}}$ from 1.87 to $2.74 \mu \mathrm{m}$ and $\mathrm{R}_{\mathrm{z}} 9.82$ to $13.5 \mu \mathrm{m}$. In the case of smooth cutting zone and rough cutting zone surfaces it was not observed any influence of SOD on surface quality.

- Analysing the 3D surfaces topography and 2D roughness profiles it was observed that the peaks, craters and valleys of the surface are asymmetrical and the variation is not constant. On the initial damage zone it can be observed that by increasing the SOD the max. valley depths increase up to $8 \mu \mathrm{m}$ and the max. peak heights increase up $5 \mu \mathrm{m}$.

- To improve the CFRP part accuracy and surface roughness, it is recommended to minimize the SOD.

This work was supported by a grant of the Romanian National Authority for Scientific Research and Innovation, CNCS/CCCDI-UEFISCDI, project number PN-III-P2-2.1-BG-2016-0216, within PNCDI III, Technical University of Cluj-Napoca through the research Contract no. 2001/12.07.2017, Internal Competition CICDI-2017 and the H2020 AMaTUC project (GA 691787).

\section{References}

1. D. K. Shanmugam, Composites. Part A 39, 923-929 (2008)

2. I. A. Popan, A. I. Popan, Acta Tehnica Napocensis 60 II, 251-254 (2017)

3. D. Liu, Y. Tang and WL. Cong, Composite Structures 94, 1265-1279 (2012)

4. P. Bere, E. Sabau, L. Hancu, A. Popescu, AJME, 11 (4), 128-131 (2013)

5. M. S. Alsoufi, International Journal of Mechanical Engineering and Applications 5(1), $1-14(2017)$

6. J. Wang, Int J Adv Manuf Technol, 15, 757-68 (1999) 
7. I. A. Popan, N. Balc, A. Carean, A. Luca, A. Miron, ICAMaT 7th International Conference on Advanced Manufacturing Technologies, 760, 409-414 (2015)

8. M. Ramulu, S. Kraja, 33 ${ }^{\text {rd }}$ International SAMPE Proceedings, 33, 1327-1339 (2002)

9. J. Carach, S. Hloch, P. Hlavacek, J. Scucka, P. Martinec, J. Petru, T. Zlamal, M. Zelenak, P. Monka, D. Lehocka, J. Krolczyk, International Journal of Advanced Manufacturing Technology 82, 1747-1752 (2016)

10. H. Bulea, R Paunescu, A.C. Filip, Applied Mechanics and Materials 760, 397-402 (2015)

11. A. C. Filip, M. Vasiloni, L. A. Mihail, MATEC Web of Conferences, 94, (2017)

12. I. A. Popan, N. Balc, A. I. Popan, R. Curta, iCAT, ISSN 1992-5093, (2010)

13. I. A. Popan, N. Balc, A. I. Popan, MSE, MATEC Web Conf.,121 (2017)

14. M. C. Kong, D.A. Axinte, W. Voice, Journal of Materials Processing Technology 210, 573-584 (2010)

15. E. Lemma, F. L. Chen, Compos Struct, 57, 297-303 (2002).

16. M. Ramulu, D. Arola, Composites, 24, 299-308 (1993)

17. S. Vasanth, T. Muthuramalingam, HPC 2016 - CIRP, Procedia CIRP 46, 139-142 (2016)

18. I. A. Popan, N. Balc, A. I. Popan, R. Pacurar, The $4^{\text {th }}$ International Conference on Additive Technologies; iCAT, ISSN 1992-5093, (2012)

19. P. Bose1, A. Dhanawade, Journal of the Association of Engineers, India 86(3-4) (2016)

20. I. A. Popan, N. Balc, A. I. Popan, IMT, Annals Of Oradea University. Fascicle Of Management And Technological Engineering XIX (IX), ISSN 1583-0691, 4.86-4.90 (2010)

21. A. C. Filip, H. Bulea, Advances in Production, Automation and Transportation Systems, ICAPS, 201-205, (2013)

22. A. Miron, N. Balc, I. A. Popan, C. S. Borzan, P. Bere, AJME 11(2), 87-92 (2013)

23. D. Lehockáa, J. Klichb, J. Foldynab, S. Hloch, ICMEM 2016, Procedia Engineering 149, $236-244$ ( 2016 )

24. D. K. Shanmugama, S. H. Masoodb, Journal of Materials Processing Technology, (2003)

25. D. K. Shanmugam, J. Wang, H. Liu, International Journal of Machine Tools \& Manufacture 48, 1527-1534 (2008)

26. P. Löschner, K. Jarosz, P. Niesłony, ICMEM, Procedia Engineering 149, 276 - 282 (2016)

27. F. L. Chen, E. Siores, Journal of Material Technology 135, 1-5 (2003)

28. *** http://shop1.r-g.de/en/art/615400 Material specifications 
